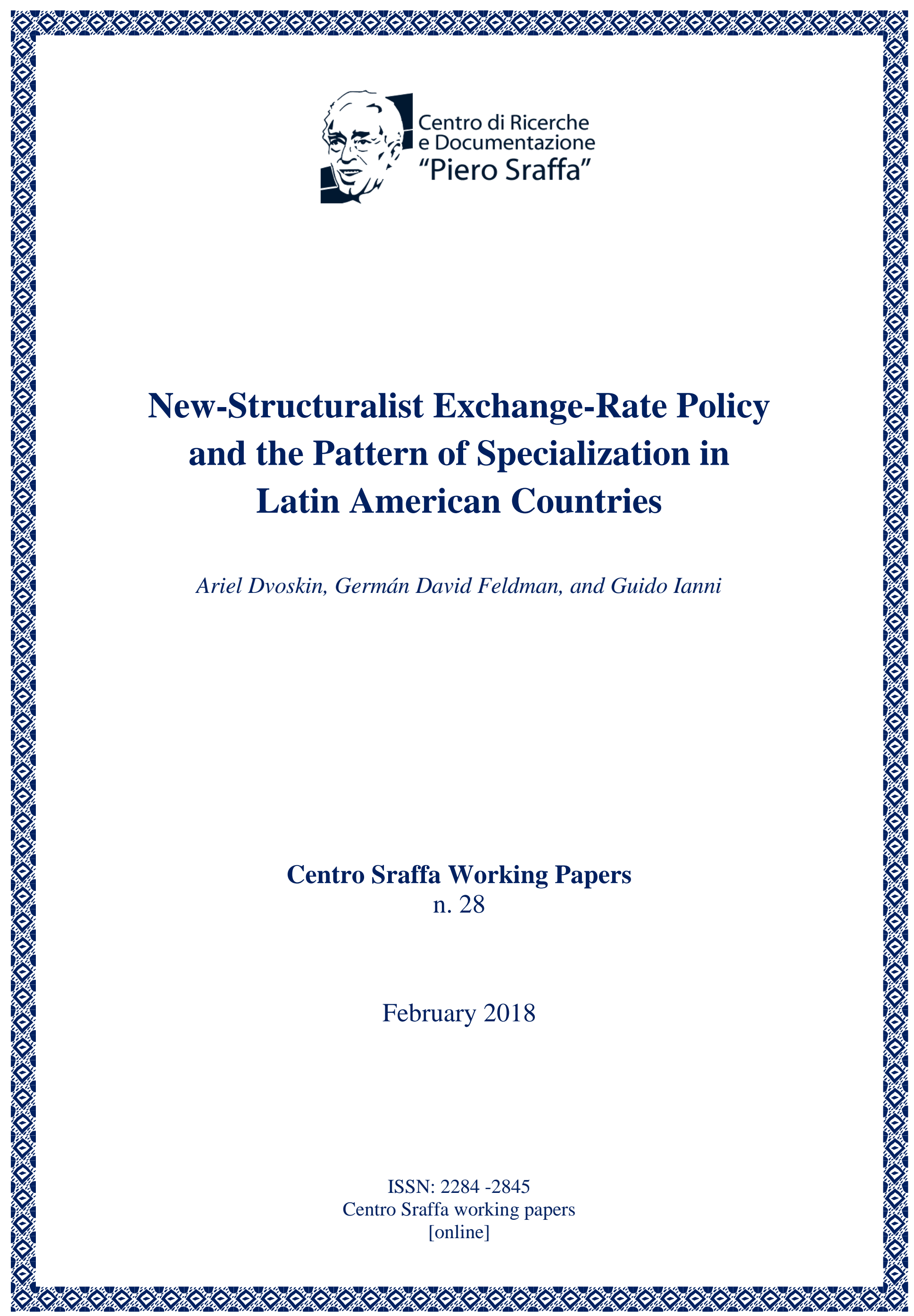




\title{
New-Structuralist Exchange-Rate Policy and the Pattern of Specialization in Latin American Countries
}

\author{
Ariel Dvoskin $^{a}$, Germán David Feldman $^{b}, \&$ Guido Ianni ${ }^{a}$ \\ ${ }^{a}$ CONICET - IDAES/UNSAM \\ ${ }^{b} I D A E S / U N S A M$
}

\begin{abstract}
The present article critically examines the transmission channels between the real exchange rate and output growth adduced by the so-called New-Structuralist doctrine. It is shown that the assumptions under which the mechanisms work are highly restrictive, and hence, are generally inadequate to explore the problem of economic development in Latin American peripheral countries. In view of this, the potential risks associated with a policy of devaluation are warned.
\end{abstract}

Keywords: Dual economies; Economic growth; New-Structuralism; Pattern of Specialization; Real Exchange Rate

JEL Codes: B22; E11; F43

\section{Introduction ${ }^{1}$}

In the last years, we have witnessed the emergence of a vast literature on development models for peripheral economies, known as «New-Structuralism» ${ }^{2}$ (henceforth, NS),

\footnotetext{
${ }^{1}$ A preliminary version of this article was presented at the 2nd New Developmentalism's Workshop, 'Theory and Policy for Developing Countries', São Paulo, August 4-5, 2017 and at Research Seminar of the Institute of Economics - Federal University of Rio de Janeiro (IE-UFRJ), August 8, 2017. We would like to thank the participants of both events for their comments and suggestions. We would also like to thank Saverio Fratini and an anonymous referee for their constructive comments and suggestions. All the remaining errors are ours.

${ }^{2}$ The term «New-Structuralism» has been employed in the literature in a broader sense: it refers to the contributions of the Economic Commission for Latin American Countries (ECLAC) in different fields of economics, from the 1990 onwards (structural reforms, globalization, innovation, macroeconomic volatility, etc; for a revision of this literature, see Bielschowsky, 2009). Here however, we will only discuss those works that, following ECLAC's tradition, explore the link between exchange rate policy and economic growth. The main proponents of this view are Ros and Skott (1998), Frenkel and Ros (2006), Rodrik (2008), Razmi, Rapetti, and Skott (2012), Rapetti (2013, 2016), Neto and Lima (2017), Ros (2016), and Damill and Frenkel (2017).
} 
which views the real exchange rate as the key variable to achieve sustained economic growth. To formalize this view, NS has recourse to a «dual economy» model, a notion firstly introduced by Lewis (1954), and identifies two strikingly different productive sectors within a peripheral economy: a sector of high productivity, able to compete in the international markets at current prices (sector $\mathrm{T}$, or the «tradable sector») and a second sector of low productivity, which is forced to sell its output in the domestic market (sector NT, or the «non-tradable» sector). ${ }^{3}$ The fact is that sector T, typically the industry, is also envisaged as the most dynamic sector in terms of job creation, innovation and productivity growth. In the short run, a rise in the exchange rate would accelerate economic growth mainly through its expansionary effects on employment and exports of sector $\mathrm{T}$. In the medium run, the increase in the relative profitability of the most dynamic sector would induce a rise of its share in output. Finally, in the long run, the higher average rate of profits would trigger a profit-led-growth path. ${ }^{4}$

The objective of this article is to critically assess the transmission channels adduced by NS. To this end, in section II we present a model for a small peripheral economy opened to trade and capital flows that will allow us a) to examine the mechanisms envisaged by this literature to ascertain a relationship between distribution and growth and b) to characterize the pattern of specialization of the economy as a particular problem of choice of techniques.

In regard to objective a), we will see in section III that NS presents three kinds of limitations. First, when the so-called «short-term» effects are addressed, a high realwage elasticity of labour demand is assumed without sufficient justification, coupled with a demand for exports that is able to absorb any excess of production over internal consumption. Second, we also find problems with the «medium» and «long-term» mechanisms. Here, not only is it assumed that investment demand is able to avoid any realization problem, but, more generally, the approach is incompatible with the uniformity of returns on capital in an economy that is fully opened to capital flows. Finally, we show that the results in terms of employment and production are indeterminate, since the possibility of wage inflation indirectly caused by devaluation (namely, through its effects on output and employment) may eventually revert the allegedly positive effects on growth.

As regards objective b), the determination of the productive structure in terms of cost-minimizing technical choices will allow us to inspect, in section IV, the implica-

\footnotetext{
${ }^{3}$ The taxonomy «Tradable vs. Non-Tradable» is misleading, since it may give the wrong impression that a particular sector intrinsically belongs to one of these categories, when this classification actually depends on income distribution and technical coefficients. However, to keep the exposition as simple as possible, in the main text we will stick to the standard terminology.

4 Actually, within this literature it is possible to identify a second position, known as «New-Developmentalism» (see Bresser; 2008; Oreiro et al. 2015), that inverts the productive structure of the economy: sector $\mathrm{T}$ produces and exports primary commodities and the industrial sector, potentially more dynamic, is unable to export its production. According to this view, the role of the exchange rate is to close the competitiveness gap of industry to boost an export-led growth path. We shall not discuss here the scopes and limits of this second position (we hope to do this in a future contribution).
} 
tions of inverting the pattern of specialization assumed by NS. In particular, the potentially drastic magnitude of devaluation necessary to boost the development of the industrial sector may sharply increase the domestic price of those goods that are already tradable. If some of these goods are necessary consumption goods (e.g. corn), or inputs of these goods (e.g. oil), as is the case for some Latin American economies, this rise may trigger wage resistance and possibly eliminate the initial reduction of labour costs in foreign currency. Curiously enough, this kind of wage inflation, in this case directly caused by devaluation, has been ignored or neglected by New-Structuralist authors. Finally, we shall see in section $\mathrm{V}$ that the attempt to use the exchange rate as an instrument to improve the international competitiveness of one particular sector may well have the undesired effect of damaging another industry that was already competitive. Section VI concludes.

\section{Analytical Framework ${ }^{5}$}

We follow New-Structuralist authors and conceive a small open economy with persistent unemployment and two productive sectors: an industrial sector (I) and a primary sector (C) (or services). The sectors distinguish themselves by two main features: i) the productive methods employed and ii) the destination of production.

Regarding the first aspect, NS scholars assume that commodity I is produced by labour and an imported capital good, while $\mathrm{C}$ requires labour and a fixed factor, typically land. Commodity prices can be represented by the following equations:

$$
\begin{gathered}
p_{C}^{S}=w l_{C}(1+r)^{6} \\
p_{I}^{S}=\left(w l_{I}+k E p_{K}^{*}\right)(1+r)
\end{gathered}
$$

where $p_{C}^{S}$ and $p_{I}^{S}$ stand respectively, for the supply prices of commodities C and I. These prices represent the minimum amount of money per unit of output that producers must receive to regularly (under «normal conditions») deliver each commodity on the market. Additionally, $w$ stands for the nominal wage rate, $r$ for the normal rate of profits, $l_{C}$ and $l_{I}$ are the unitary labour requirements of sectors $\mathrm{C}$ and $\mathrm{I}, k$ is the unitary requirement of a capital good $\mathrm{K}, p_{K}^{*}$ is its exogenously given price and $E$ is the nominal exchange rate.

It is now convenient to introduce a second notion of price, which we shall denominate demand or selling price. It represents the maximum amount of money that consumers are willing to pay for a commodity. Note that, since the domestic economy takes the international prices of $\mathrm{C}\left(p_{C}^{*}\right)$ and $\mathrm{I}\left(p_{I}^{*}\right)$ as given, once the level of the exchange rate is fixed, demand prices are univocally determined. Therefore, demand prices for commodities $\mathrm{C}\left(p_{C}^{d}\right)$ and $\mathrm{I}\left(p_{I}^{d}\right)$ are, respectively:

\footnotetext{
${ }^{5}$ This section heavily draws on Dvoskin and Feldman (2017a) and (2017b).

${ }^{6}$ Since land rent (both absolute and differential) will not play any role in the analysis, for simplicity we assume that land is free.
} 


$$
\begin{aligned}
& p_{C}^{d}=E p_{C}^{*} \\
& p_{I}^{d}=E p_{I}^{*}
\end{aligned}
$$

These four equations have seven unknowns: $E, r, w, p_{A}^{s}, p_{I}^{s}, p_{A}^{d}, p_{I}^{d}$. If we take nominal wages as given:

$$
w=\bar{w} \cdot{ }^{7}
$$

There are two degrees of freedom left. Before we suggest how to eliminate them, let us consider the abovementioned feature ii), i.e. the destination of production. Note that it is not possible to ascertain which productive sector will be internationally competitive before the relationship between demand and supply prices of each commodity is established. Hence, before income distribution is known. Therefore, the pattern of specialization of the economy will be regulated by the following conditions:

$$
p_{h}^{d} \leq p_{h}^{s}(h=C, I)
$$

Commodity $h$ will be produced and (potentially) exported only if $p_{h}^{d}=p_{h}^{s}$. In contrast, when $p_{h}^{d}<p_{h}^{S}$, sector $h$ will not be viable without protection because its normal costs of production exceed its demand price. Hence, we can derive for each commodity $h$ an $\frac{E}{w}-r$ relation that determines, for each level of the $E / w$ ratio, the maximum rate of profits that is affordable by each sector under given technical conditions and international prices. This is obtained by equalizing supply and demand prices for each commodity $h$. From conditions [1] and [3] we obtain, for sector C:

$$
r_{C}=\frac{E}{w} \frac{p_{C}^{*}}{l_{C}}-1
$$

And from [2] and [4] we get, for sector I:

$$
r_{I}=\frac{E}{w} \frac{p_{I}^{*}}{\left(l_{I}+k \frac{E}{w} p_{K}^{*}\right)}-1
$$

The left-hand side of Figure 1 represents the shape of these curves:

Figure 1: $E / w-r$ curve
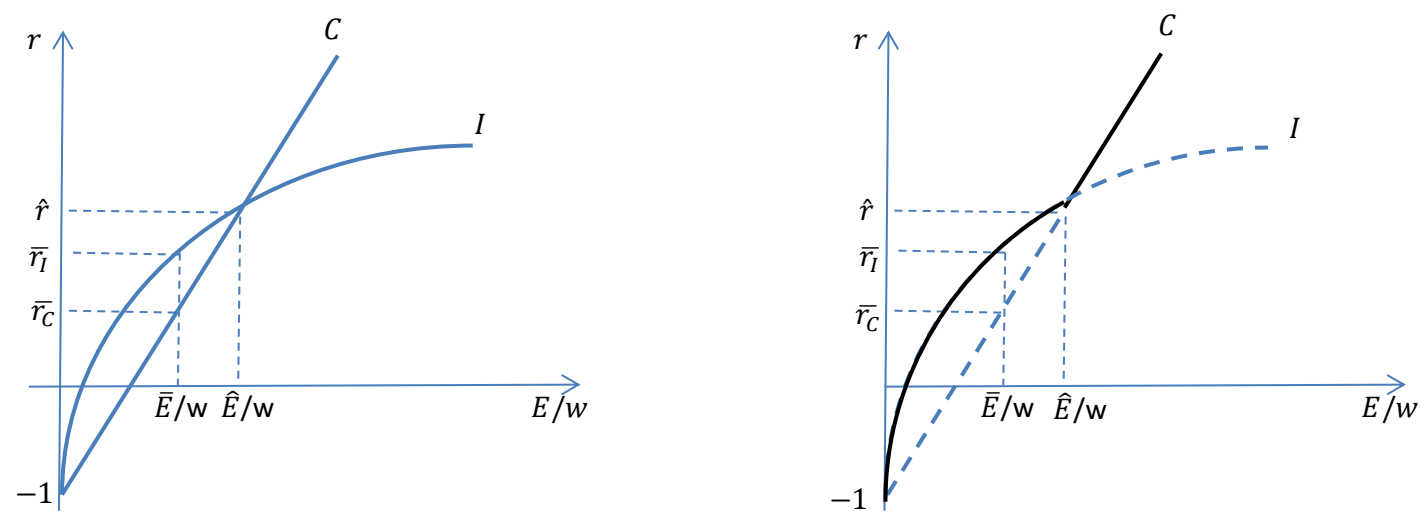

\footnotetext{
${ }^{7} \mathrm{NS}$ assumes that the level of money wages is the result of the negotiation between trade unions and firms, and hence it is an exogenously given variable.
} 
The curves can be used to determine the pattern of specialization of the economy. To see this, let us first define the real wage $\omega$ for a given consumption basket $\left(c_{C} ; c_{I}\right)$ as:

$$
\omega=\frac{w}{P}, \text { with } P=E \sum_{h=C, I} c_{h} p_{h}^{*} .
$$

Therefore, the real wage $\omega$ is univocally determined once the $E / w$ ratio is known, and shows an inverse relationship with the latter. According to a well-known result of choice of techniques (see Kurz and Salvadori, 1995, ch. 5), all this means that the economy will fully specialize in the sector that, given the $E / w$ ratio - which is none other than the inverse of the real wage, $\omega$ - (or alternatively, given $r$ ), can afford the highest rate of profits (can afford the lowest $E / w$ and hence, the highest $\omega$ ).

Then, for any level $E / w<\hat{E} / w(E / w>\hat{E} / w)$ there will be full specialization in the production of I (C). In effect, if for instance: $E / w=\bar{E} / w(<\hat{E} / w)$, then $\overline{r_{I}}>\overline{r_{C}}$ and there will be no incentive to invest in sector C. The opposite occurs when $E / w>\hat{E} / w$. And only by a fluke $E / w=\hat{E} / w$, which is the level that allows the coexistence of the two sectors in the economy.

The outer envelope of the curve (black line on the right-hand side) illustrates the economically relevant pairs of $E / w$ and $r .{ }^{8}$ In analytical terms, the $E / w-r$ relationship is given by:

$$
r=\left\{\begin{array}{lll}
r_{I} & & E / w<\hat{E} / w \\
\hat{r} & \text { if } & E / w=\hat{E} / w \\
r_{C} & E / w>\hat{E} / w
\end{array}\right.
$$

The value of $\hat{r}$ is:

$$
\hat{r}=\frac{p_{I}^{*}}{k p_{K}^{*}}-\frac{p_{K}^{*}}{k p_{K}^{*}} \frac{l_{I}}{l_{C}}-1
$$

(we shall return to condition [11] in section IV).

In sum, if $E / w$ and hence $\omega$ are known, the rate of profits is residually determined. Alternatively, if $r$ is given, $\omega$ adjusts to give consistency to the price system. Finally, the level of the exogenous distributive variable determines a certain productive structure according to condition [10]. Therefore, the remaining two degrees of freedom of the price-system will be eliminated once a) the particular distributive closure and b) the specific pattern of specialization assumed by NS are considered. This will be discussed in the following section.

\section{The New-Structuralist Position}

New-Structuralist scholars assume that the nominal exchange rate is determined by the monetary authority:

$$
E=\bar{E}
$$

\footnotetext{
${ }^{8}$ Note that, with more than two commodities, in general there will be no $E / w$ ratio that will allow the coexistence of all sectors. On this point, see Steedman (1999, p. 272) and Baldone (2001).
} 
Since the $E / w$ ratio is given, the rate of profits emerges as a residual magnitude from [10]. The level of $r$ is in turn determined once the pattern of specialization assumed by NS is specified. In this respect, NS assumes that sector I is able to compete in the international markets at the given prices (sector I is the $\mathrm{T}$ sector); and sector $\mathrm{C}$ is a relatively backward sector, whose production is only sold in the domestic markets (sector $\mathrm{C}$ is the NT sector). ${ }^{9}$ In the light of our model, the implied pattern of specialization is such that $E / w=\bar{E} / w(<\hat{E} / w)$ in Figure 1. And hence, that the rate of profits is determined at the level $r_{I}$ in equation [10], that is:

$$
r=r_{I}=\frac{E}{w} \frac{p_{I}^{*}}{\left(l_{I}+k \frac{E}{w} p_{K}^{*}\right)}-1
$$

Note that, while in the absence of protection commodity $\mathrm{C}$ should not be domestically produced, NS assumes that this good is intrinsically non-tradable (it is not subject to international competition), and hence its demand price is univocally determined by its domestic supply price. This implies that condition [3] must be replaced by:

$$
p_{C}^{d}=p_{C}^{S} .
$$

Equations [1]-[2]-[3A]-[4]-[5]-[10A]-[12] determine the following unknowns:

$$
\left\{p_{I}^{s}, p_{c}^{s}, p_{I}^{d}, p_{C}^{d}, w, r, E\right\}
$$

\subsection{Short-run mechanisms}

According to NS, the rise in $E$ exerts an expansionary effect through three mechanisms, all induced by the subsequent fall in $\omega$. It is central to trigger the entire process that NS postulates a negative relationship between labour demand in sector I $\left(L_{I}\right)$ and $\omega$. Hence, the first effect of devaluation is the rise in $L_{I}$, which in turn causes an expansion of industrial output, $y_{I}$, represented by a «Cobb Douglas» production function $y_{I}=f\left(K, L_{I}\right) .^{10}$

$$
\uparrow E / w \rightarrow \uparrow p_{I} \rightarrow \downarrow \omega \rightarrow \uparrow L_{I} \rightarrow \uparrow y_{I}
$$

\footnotetext{
${ }^{9}$ Therefore, the small peripheral economy exports commodity $I$ in exchange for imports of the capital good, $K$. No particular result of the current account is assumed by NS scholars (see e.g. Neto and Lima, 2017 , pp. 795 and 798). If there is a current account surplus, the implicit assumption is that the country accumulates reserves of foreign assets. While in case of current account deficits, since the economy is small in financial terms, it is argued that it can finance this imbalance indefinitely through capital inflows (ibid., p. 795).

${ }^{10}$ The function $f(\cdot)=A \widetilde{K}^{\gamma} K^{\alpha} L_{I}^{1-\alpha}$ is assumed to present decreasing marginal returns and increasing returns to scale, which, to be compatible with free competition, are assumed to be external to the firm and internal to the industry ( $\widetilde{K}^{\gamma}$ measures the external effect). This is allegedly due to «externalities in the learning process» (Rapetti, 2013, p. 12). Note that these conditions are highly restrictive since "...the economies of production on a large scale can seldom be allocated exactly to any one industry: they are in great measure attached to groups, often large groups, of correlated industries" (Marshall, cited by Sraffa, 1926, p. 540). It seems therefore arbitrary to assume that the externalities that affect sector I do not have an influence on sector $\mathrm{C}$. The assumption is tantamount to assuming the total disconnection among productive sectors, ignoring the possible input-output relations that generally emerge among them.
} 
These expansionary effects are not restricted to sector I, but involve sector C too. Firstly, because the expansion of $y_{I}$ increases aggregate income and, therefore, the demand for $\mathrm{C}\left(D_{C}\right)$ («income effect»).

$$
\uparrow E / w \rightarrow \downarrow \omega \rightarrow \uparrow L_{I} \rightarrow \uparrow y_{I} \rightarrow \uparrow D_{C} \rightarrow \uparrow L_{C} \rightarrow \uparrow \mathrm{y}_{\mathrm{C}}
$$

Second, because the rise in $q \equiv \frac{p_{I}}{p_{C}}$ increases the demand for -the now relatively cheaper- good C («substitution effect»).

$$
\uparrow E / w \rightarrow \uparrow q \rightarrow \uparrow D_{C} \rightarrow \uparrow L_{C} \rightarrow \uparrow y_{C}
$$

To ascertain the validity of these three mechanisms it is necessary to make two kinds of observations: first, that the negative relationship between labour demand and the real wage is a necessary yet not a sufficient condition to justify the initial increase in $L_{I}$ when $\omega$ falls. In effect, without any additional consideration, and under the plausible assumption that workers' propensity to consume is higher than capitalists' propensity, one should expect that the incentive to expand the production of commodity I will be sooner or later counterbalanced by a fall in $D_{I}$ that, ceteris paribus, is caused by the fall in the real wage. ${ }^{11}$ Hence, to ascertain that a rise in $E$ will anyway exert a favourable effect on employment, it is further necessary to justify how the excess of production of $I$ over internal consumption will be absorbed when the real wage decreases. For instance, within the marginal approach, the increased production caused by the fall in the real wage increases aggregate savings, which decreases the rate of interest and hence induces higher levels of investment. But NS does not envisage this mechanism, at least explicitly. ${ }^{12}$ And while it recognizes the possible recessive effects of the fall in the real wage, ${ }^{13}$ the issue is virtually neglected because every excess of production over internal consumption is assumed to be passively absorbed by exports $\left(X_{I}\right)$. Hence, in short-run equilibrium:

$$
X_{I}=y_{I}-D_{I} .
$$

Therefore, this short-run adjustment presumes the absence of effective-demand problems.

Behind the idea that the demand for exports is infinitely elastic at current prices we find NS authors arguing that the economy is sufficiently «small», i.e. an economy that takes the selling price of I as given. Note however that for this condition to hold it is only necessary that neither the domestic method of production nor domestic income distribution are relevant magnitudes to determine the international price of commodity I; and hence it does not need assume that the ratio of exports to global production of I is of any particular magnitude (as long as this proportion is smaller than 1). ${ }^{14}$

\footnotetext{
${ }^{11}$ On this point, see Garegnani (1978, p. 343).

${ }^{12}$ For reasons of space, it is not possible to deal with this issue here, but labour capital substitution, accepted by NS, implies the existence of a negative relationship between investment and the rate of interest (See Dvoskin and Petri, 2017).

${ }^{13}$ Frenkel and Ros (2006, p. 635), Razmi (2007), Rapetti (2013, p. 6, fn. 9).

${ }^{14}$ To link the assumption of given prices with particular conditions of demand, it is further necessary to establish general price-quantity relations that allow univocally determining the way in which demand
} 
The second consideration refers to the bases that justify the negative (and sufficiently elastic) relationship between employment and the level of the real wage itself. Here, NS closely follows the marginal approach and argues that the fall in $\omega$ increases employment because productive processes that employ more labour per unit of output become more profitable (the so-called «labour intensity channel», see Frenkel and Ros, 2006).

The fact is, however, that this channel faces an insurmountable difficulty in the treatment of capital. ${ }^{15}$ A first difficulty within the specific context examined here is that the labour intensity channel is assumed to work in the «short run», namely with a given stock of capital goods; while on the contrary the neoclassical mechanisms of substitution are envisaged to work their effects only after sufficient time, since they incorporate the empirical fact that capital goods are specific to each technique, and hence plausibly presume that the «form» of the cooperating capital must change with the change in technique. If the available capital goods before and after devaluation are the same, it may well happen that the labour demand curve is highly inelastic, with the implication that a drastic - socially unbearable - fall in the real wage is needed to achieve a certain target level of employment. The problem is somehow hidden here because the production function assumed by NS presupposes that the same capital good is used in different proportions when the quantity of labour employed changes. But it would become immediately evident once a more general specification of the available techniques is considered. ${ }^{16}$

To see a second difficulty, let us focus first on the conditions of production of commodity $\mathrm{I}^{17}$ and consider for the moment that only one method of production exists. Given that domestic costs of production must be equal to the selling price of I, from [2] and [4] we have:

$$
1=(1+r)\left(\frac{l_{I}}{p_{I}^{*}} \frac{w}{E}+\frac{p_{k}^{*}}{p_{I}^{*}} k\right) .
$$

Notice that, as the ratio $\frac{p_{k}^{*}}{p_{I}^{*}}$ (which so to speak «transforms» units of $\mathrm{K}$ in units of $\mathrm{I}$ ) is independent of production conditions and income distribution of the domestic economy, the quantity $\frac{p_{k}^{*}}{p_{I}^{*}} k$ can be read as a magnitude that is physically homogenous with I. As a result, the kind of economy that one may infer from equation [14] is, in analytical terms, identical to a productive system in which I is produced by labour and itself. As it is the case in one-good models, it is clear then that, if one now considers the possibility of two or more productive processes for commodity I, it is possible to order these methods in terms of their relative content of labour per unit of commodity I (or capital) - given by

influences technical conditions of production and/or distribution (see Garegnani, 1983). But these relations do not seem to exist outside the very restrictive world of «well-behaved», neoclassical factor demand curves.

${ }^{15}$ See Petri (2004), for a thorough discussion of this problem within the marginal approach.

${ }^{16}$ For a detailed analysis of this problem, see Dvoskin and Fratini (2016).

17 The following discussion is, however, valid for any method of production as long as inputs consist only of imported commodities. 
the respective $l_{I} / \frac{p_{k}^{*} k}{p_{I}^{*}}$ ratio.$-{ }^{18}$ One may then conclude that the «labour intensity channel» works in the «right direction»: if we compare any two methods, a decrease in the $E / w$ ratio should discourage the employment of the method with the higher $l_{I} / \frac{p_{k}^{*} k}{p_{I}^{*}}$ coefficient. However, this result critically depends on the particular conditions of production assumed by NS. If one considers, for instance, the possibility that sector I also requires domestically produced inputs - something which is accepted in some versions of NS (see Ros, 2016, p. 234) - one should consider the influence that changes in income distribution exert on the prices of the capital goods employed. And the labour intensity channel may not work in the direction predicted by NS (in the Appendix to this article we show this possibility).

\subsection{Medium and long-run mechanisms}

The medium-run mechanisms operate through changes in the relative profitability of sectors and hence affect the composition of investment, while the longer-run ones presume an increase in its level due to the rise in the general rate of profits.

Let us consider first the medium-run mechanism. Devaluation rises commodity I's demand price $\left(p_{I}^{d}\right)$; and since C's demand price $\left(p_{c}^{d}\right)$ does not change initially, the ratio $q \equiv \frac{p_{I}^{d}}{p_{C}^{d}}$ rises too. Therefore, the actual rate of profits of sector $\mathrm{I}\left(r_{I}^{A}\right)$ increases relative to that of sector $\mathrm{C}\left(r_{C}^{A}\right)$. This change in relative profitability across sectors triggers a virtuous process of «structural change» (Rapetti, 2016, p. 259) by inducing the reallocation of resources to the relatively more productive and dynamic industry I.

$$
\uparrow E / w \rightarrow \uparrow q \rightarrow \uparrow \frac{r_{I}^{A}}{r_{C}^{A}} \rightarrow \uparrow \frac{y_{I}}{y_{C}}
$$

If we now turn our attention to the longer-run mechanism, NS postulates that capital accumulation, $\widehat{K}$, is an increasing function of the difference between the gross rate of profits, $r$, and the interest rate, $i$ (determined by its international level, $i^{*}$ ).

$$
\widehat{K}=f\left(r-i^{*}\right)
$$

And given that the decrease in the real wage has caused, for a given $i^{*}$, an increase in $\left(r-i^{*}\right)$, the rate of accumulation rises:

$$
\uparrow E / w \rightarrow \downarrow \omega \rightarrow \uparrow r \rightarrow \uparrow \widehat{K}
$$

This mechanism is known in the literature as the «development channel» (Frenkel and Ros, 2006, pp. 636-637). ${ }^{19}$

\footnotetext{
${ }^{18}$ Actually, by the $p_{I}^{*} l_{I} / p_{k_{h}}^{*} k_{h}$ ratio, if one allows the kind of capital goods to differ among each productive method $h$.

${ }^{19}$ Rapetti's «tradable-led growth» channel (Rapetti, 2016, p. 259) includes both the effects on the composition [D] and the level [E] of investment.
} 
Mechanisms [D] and [E] are not exempt from difficulties either. Let us begin with [D]. A first problem is related to the alleged increment of $q$. Since it is assumed that sector $\mathrm{C}$ works under rising costs, ${ }^{20}$ the rise in $y_{C}$ due to the action of mechanisms [B] and $[\mathrm{C}]$ would eventually cause a rise in $p_{C}$, and hence, the final effect on $q$ is a priori indeterminate. To solve this issue, NS assumes that part of the production of $\mathrm{C}$ is consumed by the Government in the amount $G_{C}$ and thus it assumes that, jointly with devaluation, contractionary fiscal policies are implemented to counteract the expansionary effects of $[\mathrm{B}]-[\mathrm{C}]$ on $y_{C}$ that neutralize the effect on $p_{C}$. In other words, fiscal policy is used as a «nominal anchor» (Rapetti, 2013, p. 7) to achieve price stability.

But let us abstract from this problem and examine how the composition of investment would react when, due to the rise in $q$, the ratio $\frac{r_{I}^{A}}{r_{C}^{A}}$ rises too. As we shall proceed to argue, this needs considering the influence that the global rate of profits exerts on the domestic rate. In effect, under the assumption of free capital mobility adopted by NS, and at the level of abstraction that we are working with, we can safely assume that the domestic rate coincides -and it is determined by- the global rate, $r^{*}$. This implies that the following condition should be introduced:

$$
r=r^{* 21}
$$

(note that this means that the $E / w$ ratio, and therefore, the real wage, is the endogenously determined variable in condition [10]).

We may now note that the effects of devaluation on the profitability of I resemble the effects caused by a technical improvement: at world prices, $p_{I}^{*}$, domestic costs of production in foreign currency decrease, and allow the sector to earn extra-profits. Let $p_{I 0}^{S}$ stand for the domestic supply price of I before devaluation. At the initial level of $E=E_{0}$, these costs allow sector I to earn the normal rate of profits, $r^{*}$. If $E_{1}$ is now the new and higher level of the exchange rate, the magnitude of the extra profits, $\rho$, is determined by the difference between the selling price of I and its domestic costs of production in foreign currency:

$$
\rho=p_{I}^{*}\left(r^{*}\right)-\frac{p_{I 0}^{S}\left(r^{*}\right)}{E_{1}} .
$$

If we abstract for a moment from the problem under consideration, and examine the more general case of a technical improvement in a closed economy, the elimination of $\rho$

${ }^{20}$ According to NS, good C is produced by labour and a fixed factor, also by means of a «Cobb Douglas» production function: $y_{C}=a L^{\beta}$, with $\beta<1$. The function exhibits decreasing marginal returns and decreasing returns to scale.

${ }^{21}$ This arbitrage condition should be more properly seen as establishing a floor for the domestic rate of profit (that is, $r \geq r^{*}$ ). In effect, while if the condition $r<r^{*}$ is verified, a persistent capital outflow would take place, the opposite condition (i.e. $r>r^{*}$ ) could last for a long time, as the experience of many Latin American countries has shown in recent years (see, for instance, Serrano and Summa 2015 for the Brazilian case). In addition, condition [16] abstracts from devaluation expectations, spreads between domestic and foreign assets due to differential default risks and the relative degrees of international liquidity of national currencies. Once these factors are admitted, and if there is sufficient reason to believe that any of them can endogenously adjust to re-establish the equilibrium of net returns, then the condition $r>r^{*}$ could be verified without implying a persistent capital inflow. 
would be the effect of the fall in the selling price of I down to its new and lower costs of production, once the more productive method is generalized through the action of competition. $^{22}$ If we now turn to the problem that concerns us, the fact is however that the alleged reallocation of resources from $\mathrm{C}$ to I is by itself unable to re-establish the equality between domestic and international returns, since this adjustment considered in isolation does not alter $p_{I}^{*}\left(r^{*}\right)$. As a result, the discrepancy between $r$ and $r^{*}$ given by [17] persists. $^{23}$

All this suggests that condition [16] would be re-established once the generalization of the domestic method of production of $\mathrm{I}$, in this case on a global scale, causes $p_{I}^{*}$ to decrease until $\rho$ disappears.

The local method would become the dominant one, either because domestic firms manage to displace foreign firms in the provision of I, and/or - in a context of free capital mobility - the latter locate their plants in the domestic economy (they transnationalize their production).

While it is true that the supply of I in the share of output has increased, this has occurred at the cost of assuming that, exclusively due to its policy of devaluation, the domestic economy has managed to become the world producer of I, i.e. an export platform. The limits of this result may be better appreciated if we note that: a) this implies abandoning the assumption that the country in question is a small price-taking country, which is at the basis of the analysis of NS; b) this highly positive effects may be very easily counteracted if other economies implement a similar policy, giving rise to a «currency war». And this seems highly plausible, if those countries attempt to avoid the fall in their own levels of output and employment, especially if this may be achieved with the aid of a policy that is at hand of almost every economy.

The development channel (mechanism [E]) suffers from at least two shortcomings. Notice first that once the influence that the international rate of profits exerts on normal domestic profitability through condition [16] is considered, one seems forced to conclude that devaluation is unable to modify the real wage, at least with the sufficient persistence to induce a process of capital accumulation as it is postulated by this channel.

Second, equation [15] presents serious problems too, since is part of a family of investment functions that belong to the so called «profit-led» growth regimes. ${ }^{24}$ In this kind of models, the path of expansion of productive capacity and the trajectory of effective demand, which has final consumption as its main component, are in principle independent from one another. As a result, over sufficient time the degree of utilization of productive capacity is endogenously determined, and may persistently diverge from its normal level. In this sense, it seems contradictory to accept that capitalists, having the

\footnotetext{
${ }^{22}$ Essentially, firms that already operate in the market are forced to decrease $p_{I}^{d}$ not to lose their market share. Moreover, it is not possible to exclude that, being now cheaper, the consumption of I increases at the expense of the consumption of other goods, and hence $p_{I}$ falls due to the action of increasing returns.

${ }^{23}$ At any rate, the affluence of resources towards sector I increases the differences between $r$ and $r^{*}$. Given that I operates under increasing returns, costs decrease, and hence, given $p_{I}^{*}\left(r^{*}\right), \rho$ rises.

${ }^{24}$ See the seminal contribution by Bhaduri and Marglin (1990).
} 
possibility to revise their investment plans to adequate them to the trend of final demand, anyway decide to keep an investment trend that implies underusing or overusing productive capacity indefinitely in the future. It is in other words not reasonable to assume that firms incur in systematic errors in their projections of future demand, even when demand behaves in a completely predictable way. In this regard, one may conceive two possible routes to re-establish the gravitation towards a normal degree of capacity utilization. On the one hand, it could be assumed that due to the existence of hysteresis or path dependence, normal utilization adjusts towards the actual rate of utilization (see, for instance, Lavoie 1996). This first route does not seem to be very promising, because the normal degree of capacity utilization is determined by both technical and institutional factors; and since there is no reason to believe that any of these factors should change during the adjustment of capacity to demand, the alleged adjustment of the normal utilization towards the actual rate seems to be more an ad hoc response to the problem than a real solution to it. ${ }^{25}$ Alternatively, it is possible to conceive that the economy tends to operate under a normal degree of capacity utilization if the level of effective demand endogenously adjusts to the trend of capacity, by assuming that investment demand itself is able to absorb any increment of production that is related to the expansion of productive capacity. But this is unsatisfactory too, since it is none other than Say's Law, or the absence of effective demand problems.

In this respect, it seems much more adequate to admit that no necessary connection exists between the rate of profits and the rate of growth of the economy. Naturally, in the capitalist system there will always exist a minimum threshold for the rate of profits below which capitalists will not be willing to invest. But this does not imply that there is a mechanical relation between the average level of the rate of profits and capitalist investment decisions. Put it more simply, which are the incentives to expand productive capacity when real wages fall, if aggregate demand does not grow at the same rate as the expansion of capacity itself? The tendency towards the normal use of capacity utilization supposes the gradual adjustment of capacity to demand, which implies that, at least partially, investment must be induced by income, in line with the «accelerator principle». ${ }^{26}$

\subsection{Wage dynamics}

Even if we accept both, that devaluation succeeds in rising $r$ and an investment function like [15], the subsequent behaviour of wages is central to evaluate the «development channel»: as NS accepts, due to the effect that devaluation indirectly exerts on the price of $\mathrm{C}$, workers may attempt to recompose their initial real wage:

$$
\uparrow y_{C} \rightarrow \uparrow p_{C} \rightarrow \downarrow E / w \rightarrow \downarrow r
$$

\footnotetext{
${ }^{25}$ See Cesaratto (2015) for a detailed criticism of the so-called Neo-Kaleckian position that takes the normal degree of utilization as an adjusting variable.

${ }^{26}$ For a recent critique of profit-led regimes along these lines, see Pariboni (2016).
} 
Moreover, due to the expansionary effect of devaluation in both sectors, unemployment $(U)$ decreases and workers' bargaining power rises, which allows them to claim for higher nominal wages:

$$
\uparrow y_{C} \wedge \uparrow y_{C} \rightarrow \downarrow U \rightarrow \downarrow E / w \rightarrow \downarrow r
$$

Hence, over sufficient time, two counterbalancing forces operate on accumulation: on the one hand, the initial rise in the rate of profits promotes capital accumulation, which, given the increasing returns in sector I raises the average productivity of the economy and allows sustaining, for a given level of real wages, a higher rate of profits. On the other hand, the higher level of employment and the rising price of $\mathrm{C}$ cause nominal wages to grow, eroding normal profitability. The conclusion is that the final effect on accumulation is indeterminate. ${ }^{27}$ The difficulty is even accepted by NS authors. "[T]he real effect of devaluation”, Rapetti admits,

...may be rapidly reversed due to a high pass-through on non-tradable prices or to real wage resistance by workers. Such outcomes are actually in line with the evidence from time series econometrics ... A quick erosion of tradable profitability would undermine the incentives to investment and capital accumulation in the tradable sector would not prosper (Rapetti, 2013, p. 21).

\section{Latin American Productive Structures and Wage Resistance}

We have just seen that NS accepts that the increase in money wages indirectly induced by devaluation may annul the alleged benefits of this policy. However, New-Structuralist scholars underestimate the more certain case of wage resistance directly triggered by the rise in the $E / w$ ratio, in this case through its positive effect on the price of the tradable commodity. This is really curious, especially if the analysis is focused on Latin American countries, in which:

i) Sector T generally produces and exports necessary consumption goods, or inputs of these goods.

ii) Sector I is a backward sector that cannot compete abroad at current international prices. $^{28}$

Interestingly enough, this pattern of specialization seems to have been recently accepted by some of the proponents of the New-Structuralist approach.

The region [Latin America] has experienced a reduction in its capacity to produce tradable goods other than commodities because the persistent increase in foreign currencydenominated unit labour costs impaired profitability of these activities. The share of complex tradable activities in GDP and employment generation dropped in favour of a rise in the importance of commodities, construction and non-tradable services. The region was de-industrialized, and to reverse this process will take time (Damill and Frenkel, 2017 p. 5).

\footnotetext{
${ }^{27}$ Moreover, if there were not increasing returns in sector I, the recovery of nominal wages would eventually eliminate the initial increase in profitability (see Ros, 2016, p. 238).

${ }^{28}$ This does not mean that the sector does not exist (see fn. 29 below).
} 
If we recall that condition [11] establishes the threshold between the two possible patterns of specialization, full specialization in sector $C$ under free trade $(r>\hat{r})$ will be more likely the lower is the labour requirement of the primary sector relative to the requirement of labour in the industrial sector, and the higher is the import coefficient of sector I (the higher is $k$ ). And in fact, both features seem to apply to many Latin American countries, which produce primary commodities under extremely favourable conditions (see, e.g. Bresser, 2008, pp. 53-55) and have a backward industrial sector, highly dependent on imported capital goods, inherited from the incomplete import-substitution experiences of past decades (these economies exhibit what Tavares, 2000, denominates «technical dependency»; see also Frenkel and Ros, 2006, p. 635).

Therefore, sector I requires a real depreciation (a rise in the $E / w$ ratio) to become internationally competitive. But then, nothing excludes that the attempt to boost the competitiveness of the sector needs, due to ii), a drastic increase in the level of the real exchange rate, which turns out to be, owing to i), socially unviable.

To visualize this, we must consider an open economy whose productive structure is such that the abovementioned features i) and ii) hold. This means that, given the rate of profits by [16], the real wage is maximized (the $E / w$ ratio is minimized) when the nominal exchange rate derived from condition $[10]$ is:

$$
E=E_{C}=\frac{w l_{C}\left(1+r^{*}\right)}{p_{c}^{*}}
$$

Conditions [1]-[2]-[3]-[4]-[5]-[10B]-[16] are enough to determine the following variables: $\left\{p_{I}^{s}, p_{c}^{s}, p_{I}^{d}, p_{C}^{d} w, r, E\right\}$. Now, notice that the assumed pattern of specialization implies that the level of $E$ that allows sector I to earn the normal rate of profits,

$$
E=E_{I}=\frac{w l_{I}\left(1+r^{*}\right)}{p_{I}^{*}-k p_{k}^{*}\left(1+r^{*}\right)}
$$

(see condition [10]), is higher than $E_{C}$. In other words, since $p_{I}^{S}\left(E_{C}\right)>p_{I}^{d}\left(E_{C}\right)$, commodity I cannot be profitably produced without protection. ${ }^{29}$

This can be seen with the help of Figure 2:

Figure 2: Sectorial exchange rates

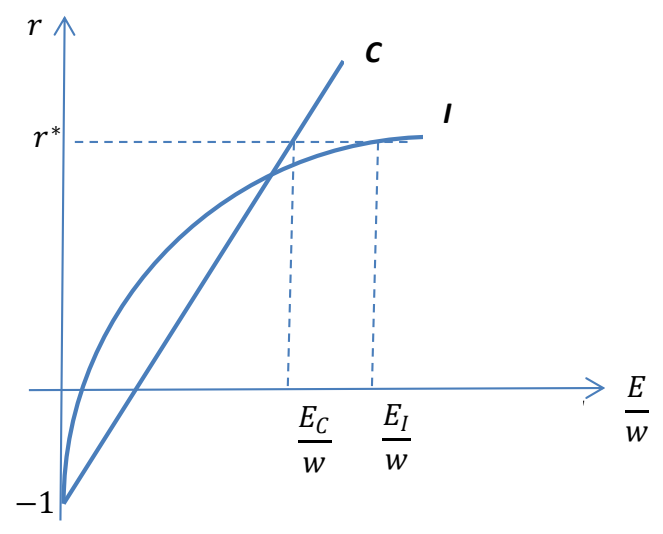

\footnotetext{
${ }^{29}$ If an import tariff on commodity I of magnitude $\tau=p_{I}^{S}\left(E_{C}\right)-p_{I}^{d}\left(E_{C}\right)$ is imposed, then this good can be profitably sold in the domestic market (it would be a non-traded good).
} 
This means that, for sector I to earn the normal rate of profits $\left(r^{*}\right)$, a rate of devaluation of the magnitude $\frac{\Delta E}{E}=\frac{E_{I}}{E_{C}}-1$ would be needed. Notice that the ratio $\frac{E_{I}}{E_{C}}$ is a sort of sectorial competitiveness index (SCI) that is equal to:

$$
S C I=\frac{E_{I}}{E_{C}}=\frac{l_{I}}{l_{C}} \frac{p_{C}^{*}}{\left[p_{I}^{*}-k p_{K}^{*}(1+r)\right]} \cdot 30
$$

And hence, for a given rate of profits, it positively depends on the degree of structural heterogeneity of the economy, namely: a) the relatively low labour productivity of sector I and b) the high import coefficients of this sector. As seen above, for Latin American peripheral economies, both factors suggest that $S C I$, and therefore the required rate of devaluation, could be drastic.

It is now easy to see why this may not be socially feasible. Let us assume that there is a minimum quantity of $\mathrm{C}(\alpha)$ that is necessary for worker's subsistence («food for the cattle»). Given $w=\bar{w}$, it is possible to determine the maximum level of the exchange rate $\left(E_{\alpha}\right)$ that allows workers to buy that quantity $\mathrm{C}$ as:

$$
E_{\alpha}=\frac{\bar{w}}{\alpha p_{C}^{*}}
$$

The implication is the following: since $E_{I}=E_{C} * S C I$, if structural heterogeneity, measured by SCI, is severe, it may well happen that $E_{I}>E_{\alpha}$. Therefore, the required rate of devaluation will be socially unviable, it will provoke full wage resistance, and will neutralize the initial effects of the rise of the exchange rate on international competitiveness.

\section{Exchange Rate Policy, Sectorial Competitiveness and Income Distribution}

In the previous section we have seen that the recourse to exchange-rate policy to promote the development of a particular sector may clash with the distributive limit. Leaving this problem aside, the temptation may be strong to use this tool to boost one particular sector in the belief that this will not be damaging for any other industry. As, for instance, Ros and Frenkel (2006, p. 635) argue: "A more depreciated real exchange rate encourages tradable activities that were not profitable before" (emphasis added). We shall see next how unfounded this presumption could be.

\footnotetext{
${ }^{30}$ Clearly, had the exchange rate raised up to $E_{I}$, the rate of profits would rise pari passu according to [10], and sector C would still be the most profitable industry. This shows that SCI is not an accurate index to determine the magnitude of devaluation needed to promote a particular sector. We will return to this point in the following section. At any rate, if we assume that $\mathrm{C}$ is produced under conditions of differential rent, which is a particularly plausible assumption in the case of Latin American economies (see e.g. Bresser, 2008, who argues that C yields «Ricardian Rents»), devaluation increases the magnitude of the rent but it does not affect the average rate of profits. For a formalization of differential rent in the context of the theory of international trade, see Birolo (1981) and Dvoskin and Feldman (2017a) for the specific context of Latin American countries.
} 
The analysis will be conducted under the assumption that many (and not just two) commodities are produced in the economy, and we will examine the effect of changes in the $E / w$ ratio on some particular industries. We shall continue to assume that a generic industrial good $h$ is produced by labour and an imported capital good. To simplify the notation, prices are expressed in terms of labour commanded $(w=1)$. Let us start by defining the ratio:

$$
C C_{h}=\frac{p_{h}}{E p_{h}^{*}} .
$$

$C C_{h}$ (for «comparative costs») is an index of competitiveness that measures the relationship between domestic and international costs of production in sector $h$. The higher the level of $C C_{h}$, the stronger the relative backwardness of industry $h$ is supposed to be. In particular, when $C C_{h}>1(\leq 1)$, the sector cannot (can) compete at the prevailing international prices. If we now consider two industrial sectors $i$ and $j$ such that $C C_{i}<C C_{j}$, it follows from [20] that sector $i$ has a lower degree of relative backwardness than sector $j$. This index is nothing but the usual definition of comparative advantages, given that $C C_{i}<C C_{j}$ implies that:

$$
\frac{p_{i}}{p_{j}}<\frac{p_{i}^{*}}{p_{j}^{*}}
$$

Let us now consider the situation in which condition $C C_{h}>1(h=i, j)$ holds. If, additionally, $C C_{i}<C C_{j}$, devaluation should allow sector $i$ to produce and export before sector $j$. This situation is represented in Figure 3, in which we illustrate the relative costs of production of two generic commodities $i$ and $j$ as decreasing functions of $E$.

Figure 3: Comparative costs $\left(r=r_{1}\right)^{31}$

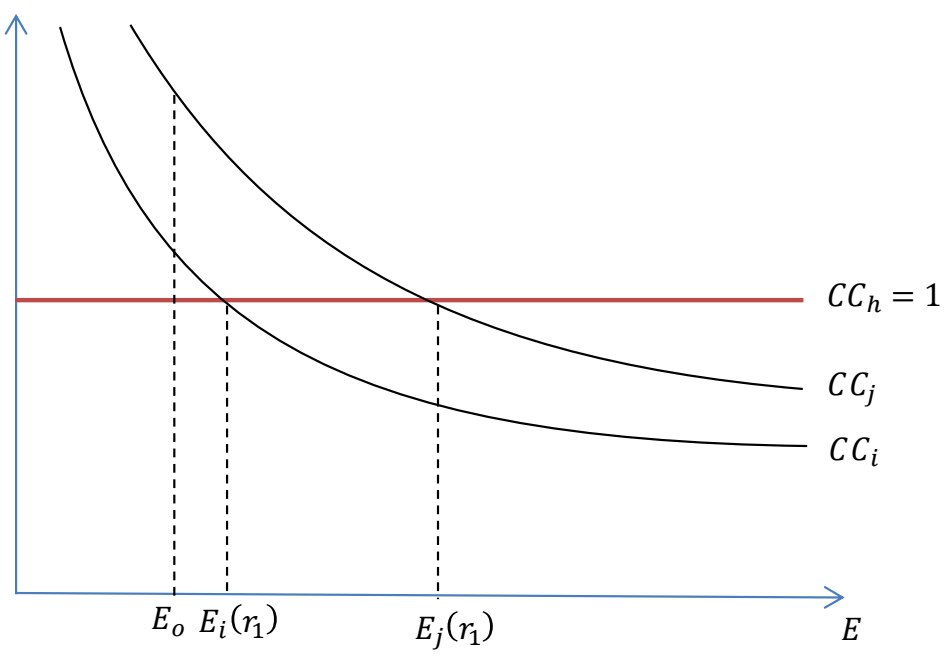

Given the underlying conditions of production of the generic sector $h$, an alternative representation of [20] is:

\footnotetext{
${ }^{31}$ An example of technical coefficients, rate of profits and international prices that reproduce this position of the comparative costs curves is the following:$$
r=50 \%,\left(l_{i} ; p_{k}^{*} k_{i}\right)=(1 ; 1 / 4),\left(l_{j} ; p_{k}^{*} k_{j}\right)=(5 / 3 ; 1 / 3) \text { у }\left(p_{i}^{*} ; p_{j}^{*}\right)=(1 ; 1) .
$$ 


$$
C C_{h}=\frac{(1+r) l_{h}}{E p_{h}^{*}}+\frac{(1+r) p_{k}^{*} k_{h}}{p_{h}^{*}} .
$$

If we choose units of measurement such that $p_{h}^{*}=1(h=i, j)$, the straight line $C C_{h}=$ 1 defines a «threshold of sectorial competitiveness». Notice that, for $r=r_{1}$, the initial level of the exchange rate, $E=E_{0}$, is too low for both sectors $i$ and $j$ to be internationally competitive. Furthermore, since $C C_{i}<C C_{j}$, sector $i$ is supposed to be able to export its production before sector $j$. In effect, if $E \epsilon\left(E_{i}\left(r_{1}\right) ; E_{j}\left(r_{1}\right)\right)$, it follows that $C C_{i}<1<$ $C C_{j}$ (only $i$ is competitive). While if $E>E_{j}$ the competitiveness of both sectors is ensured. At first glance, everything seems to support the robustness of $C C$ as an index of relative sectorial efficiency.

The case represented in Figure 3 is, however, highly restrictive, since it illustrates a situation in which $C C_{i}<C C_{j}$ for every value of $E$ (notice that the $C C$ curves do not intersect). It is easy to verify that, if we choose the units of account so that the international prices are equal to one, the condition:

$$
\left(l_{i}-l_{j}\right)\left(k_{i}-k_{j}\right) \geq 0^{32}
$$

is necessary and sufficient to avoid an economically relevant intersection ${ }^{33}$ of the curves of comparative costs. However, it is not difficult to conceive a situation in which [23] does not hold and the curves $\mathrm{CC}$ intersect, for instance, above the threshold of competitiveness. This is illustrated in Figure 4:

Figure 4: Comparative costs $\left(r=r_{1}\right)^{34}$

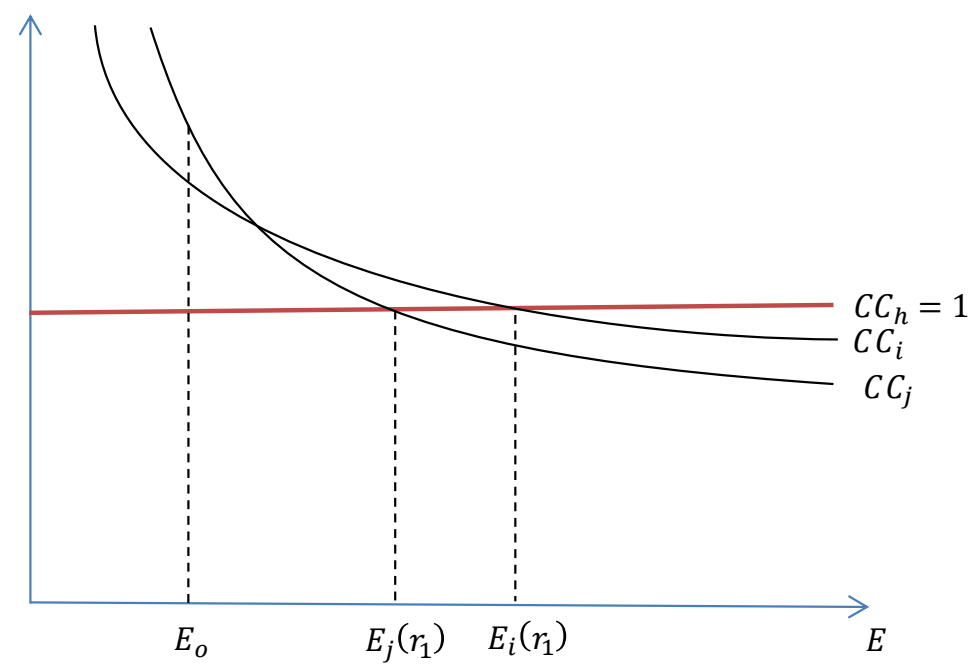

${ }^{32}$ To derive this condition, consider the equality between $C C_{i}$ and $C C_{j}$. The level of $E$ that allows both industries to be simultaneously competitive abroad is given by $E=-\frac{l_{i}-l_{j}}{k_{i}-k_{j}}$. Therefore, $\left(l_{i}-l_{j}\right)$ must be of the same sign as $\left(k_{i}-k_{j}\right)$ for this level of $E$ to be negative and hence economically irrelevant. Notice too that the profit rate does not play any role in this condition.

${ }^{33}$ In the case illustrated in Figure 3 , both factors are negative, so that $C C_{i}$ has a lower intercept $\left(p_{k}^{*} k_{i}^{*} / p_{i}^{*}\right)$ and a lower slope $\left(l_{i} / p_{i}^{*}\right)$.

${ }^{34}$ An example of technical coefficients, rate of profits and international prices that reproduce this position of the comparative costs curves is the following:

$$
r=50 \%,\left(l_{i} ; p_{k}^{*} k_{i}\right)=(1 ; 1 / 2),\left(l_{j} ; p_{k}^{*} k_{j}\right)=(5 / 3 ; 1 / 3) \text { у }\left(p_{i}^{*} ; p_{j}^{*}\right)=(1 ; 1) .
$$


At $E=E_{0}$, condition $C C_{h}>1$ is again verified for $h=i, j$, so neither sector $i$ nor sector $j$ can compete in the international markets. Moreover, since $C C_{i}<C C_{j}$, one may once again expect that devaluation allows sector $i$ to export its production before sector $j$. Nevertheless, the opposite occurs. Specifically, if $E \epsilon\left(E_{j}\left(r_{1}\right) ; E_{i}\left(r_{1}\right)\right)$, we would observe that $C C_{j}<1<C C_{i}$ : sector $j$ is competitive while sector $i$ is not.

Criterion $C C$ is not sufficiently general to predict which sector crosses the threshold of competitiveness first, even if (we provisionally assume that) the nominal wage and the rate of profits remain constant when the exchange rate varies. The reason is that the straight lines intersect above the threshold of competitiveness. One may think, anyway, that the result is exclusively due to the $C C$ criterion to be adopted. In this regard, one could employ instead the index SCI of the previous section (equation [18]), which can be alternatively defined as the ratio between the minimum level of $E$ that allows sector $h$ to get access to the world market, $E_{i}$, and any arbitrary observed level, $E_{0} \cdot{ }^{35}$ Let us rewrite equation [18] using this alternative definition of $S C I$ :

$$
S C I_{h}=\frac{E_{h}}{E_{0}} .
$$

Clearly, when $S C I_{h}>1(<1)$ the sector is not (is) competitive. According to this criterion, $i$ is «relatively more productive» than $j$ if $E_{i}<E_{j}$ (or equivalently, if $S C I_{i}<S C I_{j}$ ).

It is easy to show that $S C I$ correctly predicts which sector becomes competitive first in the situations represented by Figures 3 and 4. Let us also note that although the absolute magnitude of the individual $S C I_{h}$ depends on the effective value of $E$ used in [18'], namely $E_{0}$, the relative position of sectors according to this index is independent of this magnitude, since changes in $E$ affect all sectors in the same proportion. In this regard, $S C I$ is more robust than $C C$, since, as we have seen, the relative position of the CC curves does change with $E$. However, the $S C I$ index is not free of difficulties either.

In fact, the careful reader may have already noticed that the value of each $S C I_{h}$ depends on the position of the curves of comparative costs, relative to the threshold of competitiveness. And the fact is that such position depends on the level of the rate of profits. ${ }^{36}$ In effect:

$$
S C I_{i}<S C I_{j} \Leftrightarrow E_{i}<E_{j} \Leftrightarrow \frac{l_{i}}{l_{j}}<\frac{1-(1+r) \frac{p_{k}^{*}}{p_{i}^{*}} k_{i}}{1-(1+r) \frac{p_{k}^{*}}{p_{j}^{*}} k_{j}}
$$

\footnotetext{
${ }^{35}$ For this interpretation of SCI, see for instance, Bresser (2008, p.55).

${ }^{36}$ An analogous result is also present in the case of $C C$. Although the relative position of two $C C$ curves is independent from the rate of profits, since

$$
\frac{C C_{i}}{C C_{j}}=\frac{p_{j}^{*}}{p_{i}^{*}} \frac{l_{i}+E p_{k}^{*} k_{i}}{l_{j}+E p_{k}^{*} k_{j}},
$$

variations in the rate of profits affect the absolute position of the curves. Hence, although the ordering according to $C C$ is invariant to changes in the rate of profits, which sector becomes competitive first can be modified by changes in $r$. A graphical representation of this phenomenon can also be seen by comparing Figures 4 and 5.
} 
Condition [24] shows that the relative competitiveness of sectors could be affected by changes in distribution. This issue can be appreciated in Figure 5, in which we represent the curves of comparative costs for the same technical coefficients employed in Figure 4, but for a lower rate of profits, $r_{2}\left(<r_{1}\right)$.

Figure 5: Comparative costs $\left(r=r_{2}<r_{1}\right)^{37}$

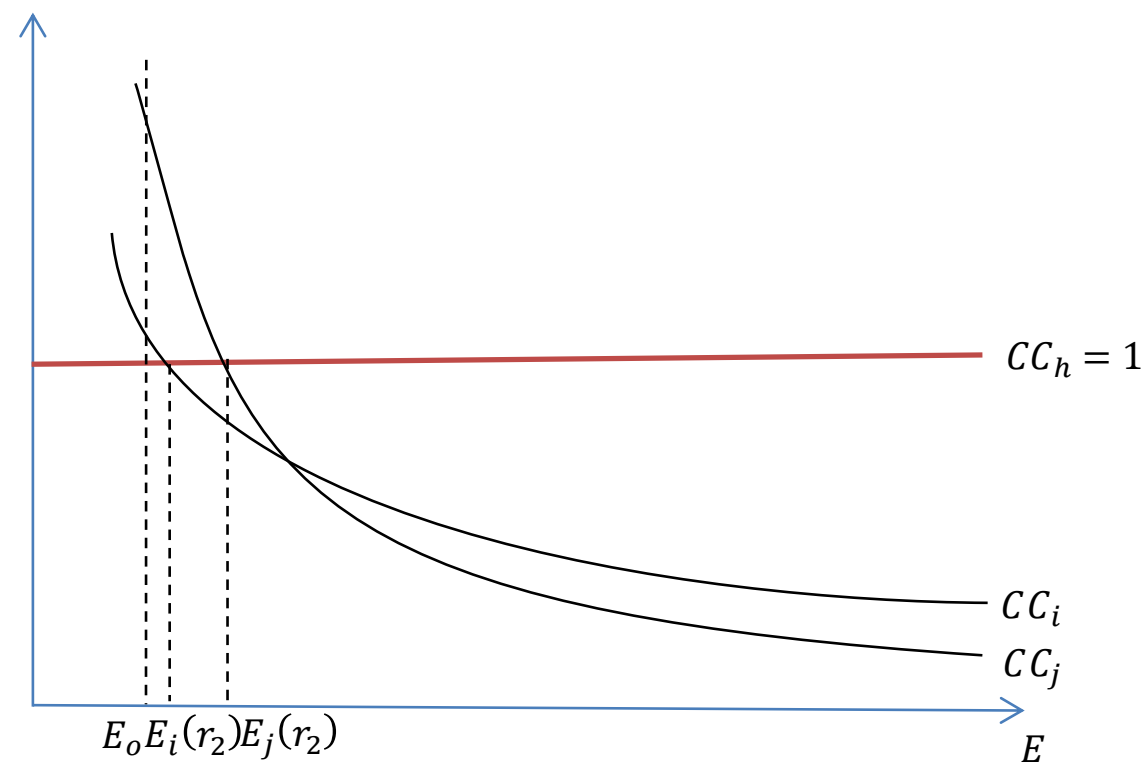

$S C I$ (and $C C$ ) predicts that sector $i$ is the first to cross over the threshold of competitiveness. If one would attempt to improve, for instance, the competitiveness of sector $i$, the necessary rate of devaluation would be given, in principle, by the magnitude $S C I_{i}$. Nevertheless, this conclusion omits that, in general, $E$ and $r$ will move in the same direction (see condition [10]) and hence, the rise in $E$ may lead to a situation as the one already described in Figure 4.

Two observations follow from this. For the first one it would be useful to represent the curve of comparative costs for sector $i$ before and after the rise in $r$ caused by devaluation. This is shown in Figure 6.

It can be seen from the figure that SCI underestimates the magnitude of the required devaluation to ensure the competitiveness of sector $i$. This is because SCI does not incorporate the subsequent rise in $r$ when $E$ rises, and hence it neglects that production costs will rise, not only because $E$ has risen, but also because $r$ has risen too. This means that devaluation itself causes the initial target level of $E$ to rise: in this case from $E_{i}\left(r_{2}\right)$ to $E_{i}\left(r_{1}\right)$. And this rise may be drastic, and therefore socially unviable for the reasons discussed in section IV.

\footnotetext{
${ }^{37}$ An example of technical coefficients, rate of profits and international prices that reproduce this position of the comparative costs curves is the following:$$
r=10 \%,\left(l_{i} ; p_{k}^{*} k_{i}\right)=(1 ; 1 / 2),\left(l_{j} ; p_{k}^{*} k_{j}\right)=(5 / 3 ; 1 / 3) \text { y }\left(p_{i}^{*} ; p_{j}^{*}\right)=(1 ; 1) .
$$ 
Figure 6: Comparative costs $\left(r=r_{1}\right.$ and $\left.r=r_{2}\right)$

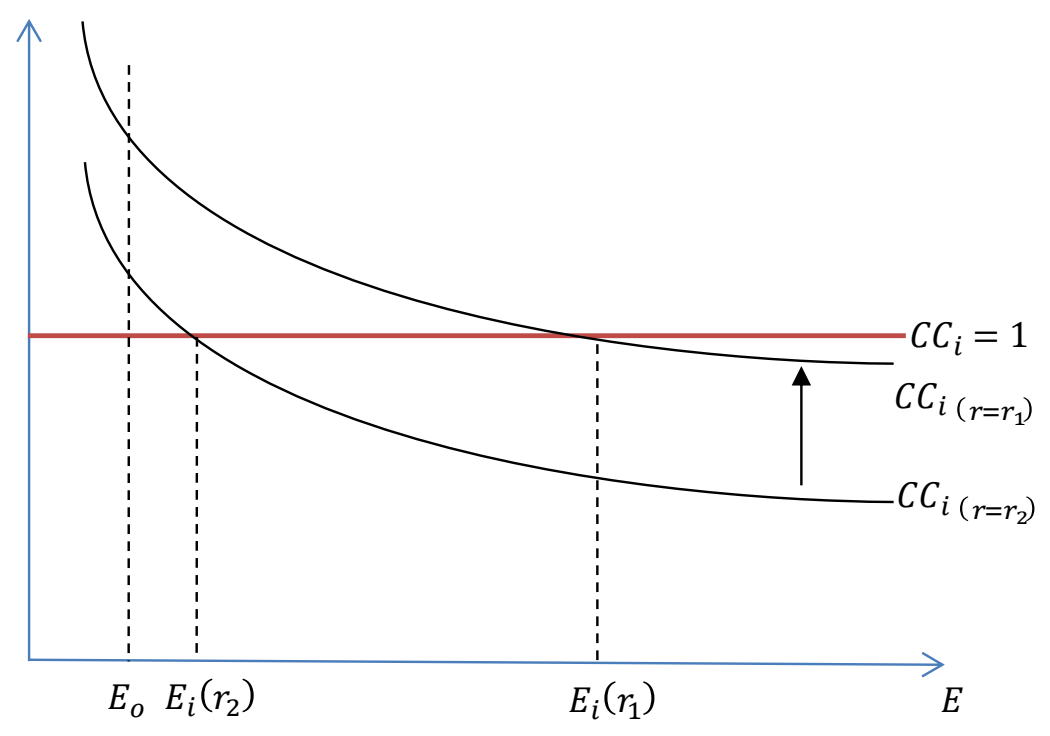

For the last observation it would be convenient to jointly represent in Figure 7, the curves of comparative costs before and after the change in the rate of profits (note that the rise in $r$ from $r_{2}$ to $r_{1}$ moves both $C C$ curves upwards, but it does not affect their relative position).

Figure 7: Comparative costs $\left(r=r_{1}\right.$ and $\left.r=r_{2}\right)$

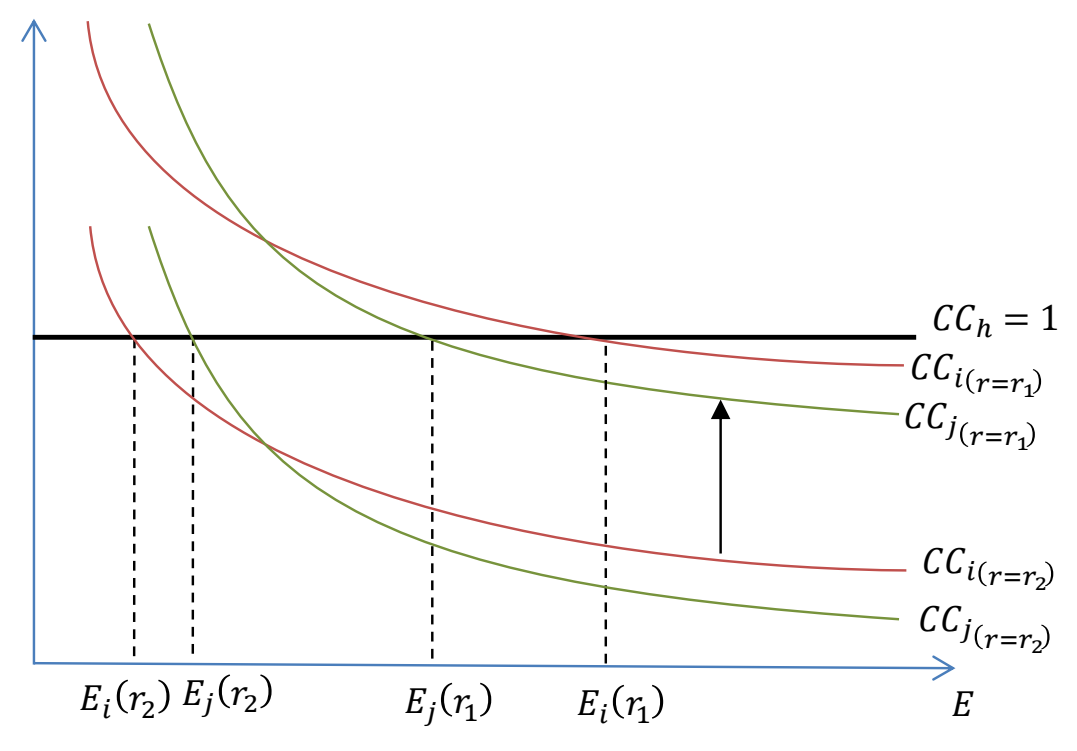

The second remark is therefore the following: a rise in $E$ to promote sector $j$, ends up, due to the change in income distribution, by excluding sector $i$, which was already competitive (actually it excludes both sectors). To see this, notice that, when $r=r_{2}$, if $E \in\left(E_{i}\left(r_{2}\right) ; E_{j}\left(r_{2}\right)\right)$ sector $i$ is competitive while sector $j$ is not. If $E$ is raised to the desired target, $E_{j}\left(r_{2}\right)$, it may happen that with the subsequent rise in $r$ to $r_{1}$, the new effective rate $E=E_{j}\left(r_{2}\right)$ is lower than the new target for sector $i, E_{i}\left(r_{1}\right)$. This means that sector $i$ has now been excluded from the global markets. Moreover, it must be noted that: 


$$
E_{i}\left(r_{2}\right)<E_{j}\left(r_{2}\right)<E_{j}\left(r_{1}\right)<E_{i}\left(r_{1}\right)
$$

and since the final level of $E$ is lower than both new targets $E_{j}\left(r_{1}\right)$ and $E_{i}\left(r_{1}\right)$, actually none of the sectors is competitive (while at the initial effective level, since $E \in$ $\left(E_{i}\left(r_{2}\right) ; E_{j}\left(r_{2}\right)\right)$, sector $i$ was). Notice finally from [25] that the rise in $r$ from $r_{2}$ to $r_{1}$ has caused an inversion of the sectorial order according to the $S C I$ index, since $E_{i}\left(r_{2}\right)<$ $E_{j}\left(r_{2}\right)$ while now $E_{j}\left(r_{1}\right)<E_{i}\left(r_{1}\right)$.

The general conclusion is the following: the fact that sectorial order depends, in general, on the rate of profits, seems to show that a purely technical index of productivity does not exist. For the same reason, one should be extremely careful to use this kind of criteria to derive policy recommendations, since they require predicting with high precision the possible reactions of the rate of profits and of the real wage to changes in the exchange rate. When these reactions are not duly considered, the attempt to develop one sector may for instance have the undesired effect of being detrimental to another one.

\section{Conclusions}

Throughout this paper we have critically explored the transmission channels from the real exchange rate to economic growth discussed by New-Structuralist literature. As we have seen, the approach postulates restrictive mechanisms that make it impossible to establish a general relationship between both variables.

In addition, we have shown that NS does not pay to the issue of the distributive conflict the attention it deserves. The reason why its proponents cannot see the problem should be clear at this point: by assuming that the industrial sector is already internationally competitive, there is no need for a drastic devaluation in order to accelerate growth. If we add the fact that the transmission channels within this position assume a sufficient wage elasticity of the labour demand curve, the need for a sharp rise of the real exchange rate in order to activate the virtuous process disappears.

We have seen that the distributive barrier is, however, a serious problem for many developing countries, Latin American economies for instance, whose productive structure is featured by an advanced sector that exports primary commodities (or inputs of these goods), while the industrial sector, potentially more dynamic, cannot compete at given world prices, and hence may need a drastic devaluation to afford the normal, internationally given, rate of profits, which may not be socially implementable.

We finish with the following consideration. Undoubtedly, from the New-Structuralist view one can derive very concrete policy prescriptions (devaluation and fiscal consolidation, among others). For these to be plausible measures, however, the relationship between the exchange rate and economic growth should not be, borrowing an expression from Marx, «purely accidental», but their causality should be firmly established. Therefore, our critical assessment of NS leads us to warn about the potential risks of such policy prescriptions: to the possible inflationary, regressive and recessive effects of 
devaluation, clearly documented within the Latin American Structuralist literature from the 1950s onwards, in this paper we have noted that the rise of the exchange rate may even generate an effect opposed to the one pursued, and worsen the competitiveness of already-competitive productive sectors.

\section{Appendix: On the Labour Intensity Channel}

This appendix discusses the labour intensity channel (LIC), according to which a rise of the $E / w$ ratio (a rise of $r$ ) should induce the adoption of productive methods that employ a larger quantity of labour per unit of output. We shall see that when the restrictive hypothesis adopted by NS regarding the conditions of production of the industrial good are relaxed, such mechanism is not generally valid. In particular, we will assume that the production of commodity I requires not only labour and an imported input, but also a capital good, M, which is domestically produced. The assumed technical conditions of production are summarized in the following equations of supply prices: ${ }^{38}$

$$
\left\{\begin{aligned}
E p_{I}^{*}= & p_{I}=(1+r)\left(l_{I} w+m_{I} p_{m}+k_{I} p_{k}^{*} E\right) \\
p_{m} & =(1+r)\left(l_{m} w+k_{m} p_{k}^{*} E\right)
\end{aligned}\right.
$$

It is possible to identify at least three criteria to determine which method employs a «larger quantity of labour»:

Criterion 1: Technique $\alpha$ employs more direct labour than another one $\beta$ if:

$$
l_{I}^{\alpha}>l_{I}^{\beta}
$$

Criterion 2: Technique $\alpha$ employs more total labour (direct and indirect) than another one $\beta$ if:

$$
l_{I}^{\alpha}+m_{I}^{\alpha} l_{m}>l_{I}^{\beta}+m_{I}^{\beta} l_{m}
$$

Criterion 3: Technique $\alpha$ employs more labour than $\beta$ if the net product under $\alpha$ is lower than under $\beta$. This means that $\alpha$ can afford a lower real wage than $\beta$ when the rate of profits is zero:

$$
\frac{p_{I}^{*}-p_{k}^{*}\left(k_{I}^{\alpha}+k_{m} m_{I}^{\alpha}\right)}{l_{I}^{\alpha}+m_{I}^{\alpha} l_{m}}<\frac{p_{I}^{*}-p_{k}^{*}\left(k_{I}^{\beta}+k_{m} m_{I}^{\beta}\right)}{l_{I}^{\beta}+m_{I}^{\beta} l_{m}}
$$

We additionally know that $\alpha$ is more convenient than $\beta$ if, at the ruling prices, it is less expensive than $\beta$ :

$$
p_{I}^{\alpha}<p_{I}^{\beta}
$$

where $p_{I}^{j}(j=\alpha, \beta)$ denotes the supply price of I under method $j=\alpha, \beta$. To see that the LIC can behave in a «perverse» way, let us consider a situation such that, at current

\footnotetext{
${ }^{38}$ The technical conditions of production of $\mathrm{C}$ are not represented here because they are of no relevance for the analysis.
} 
prices, costs of production under both methods coincide, and are also equal to the international price of I, $p_{I}^{*}$. Under these circumstances, both methods coexist. We know that when the exchange rate rises, if the rate of profits does not change, then

$$
p_{I}^{j}<p_{I}^{d}=E p_{I}^{*},
$$

since the ratio $E / w$ has increased. Due to the action of competition $r$ will rise until the condition $\min \left[p_{I}^{j}\right]=p_{I}^{d}$ is again re-established. This is a problem of choice of techniques for the open economy. The production systems can be represented by the following conditions:

$$
\left\{\begin{array}{l}
\pi^{j}=\left(1+r^{j}\right)\left(l_{I}^{j} \omega+m_{I}^{j} \frac{p_{m}}{E}+k_{I}^{j} p_{k}^{*}\right) \\
\pi_{m}^{(j)}=\left(1+r^{j}\right)\left(l_{m} \omega+k_{m} p_{k}^{*}\right) \\
\pi_{I}^{j}=p_{i}^{*}
\end{array}\right.
$$

where $\pi^{j}=p_{I}^{j} / E$ stands for the cost of production of I under method $j=\alpha, \beta, \omega=$ $w / E, r^{j}$ is the rate of profits under method $j$ and $\pi_{m}^{(j)}$ is the respective cost of production of $M$ in foreign currency. For convenience, we set $p_{I}^{*}=1$.

We know that the technique with lower production costs will be the one that can afford the highest level of $r^{j}$, given $\omega$.

Let us assume that method $\beta$ is less labour intensive than $\alpha$ under the three criteria defined above. Figure A1 illustrates a situation in which LIC behaves perversely.

Figure A1: $r-\omega$ relation

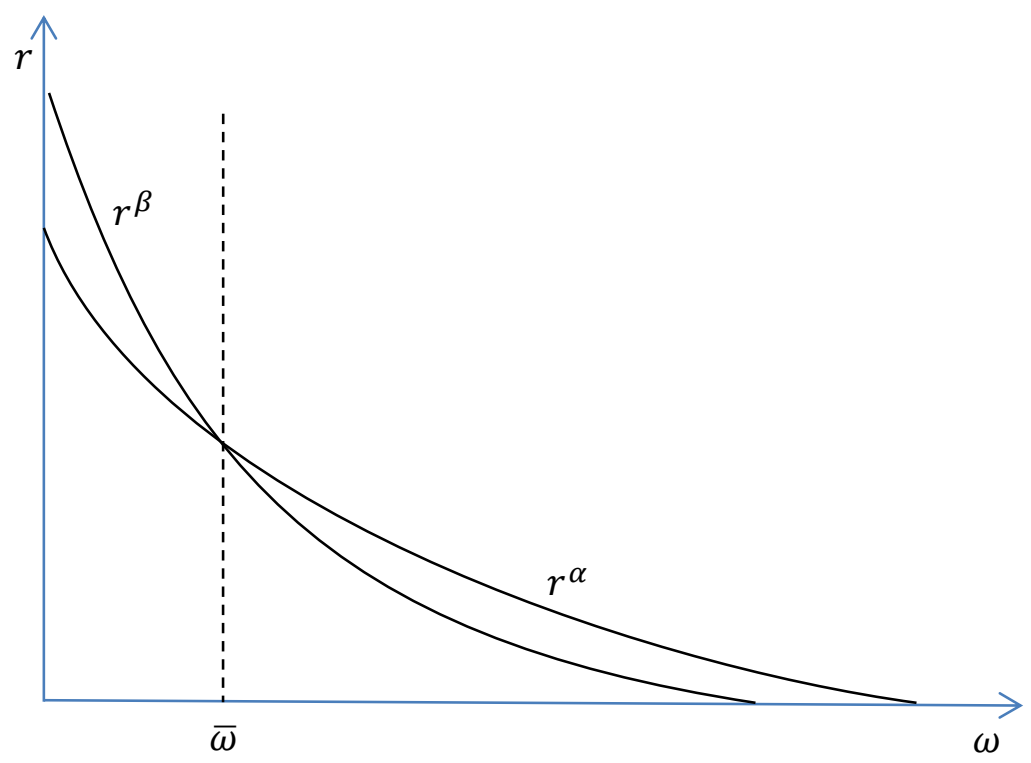

In particular, if $\omega=\bar{\omega}$ and $r^{\alpha}=r^{\beta}$, both methods can coexist. It is then clear that a necessary and sufficient condition for a fall in $\omega$ to induce the adoption of the less labour intensive technique $\beta$ is that $r^{\alpha}$ is less steep than $r^{\beta}$. Given that both curves are negatively sloped, this means that: 


$$
\left.\frac{d r^{\alpha}}{d w}\right|_{\omega=\bar{\omega}}>\left.\frac{d r^{\beta}}{d w}\right|_{\omega=\bar{\omega}}
$$

We now proceed to illustrate this possibility by means of a concrete numerical example. The first two rows of Table A1 show, respectively, the coefficients of production of I under methods $\alpha$ and $\beta$, while the third row shows the technical coefficients of commodity M. Units are chosen so that international prices of I and $\mathrm{K}$ are equal to 1.

Table A1

\begin{tabular}{|c|c|c|c|}
\hline \multirow[b]{3}{*}{$I^{\alpha}$} & \multicolumn{3}{|c|}{ Inputs } \\
\hline & Labour & $M$ & $K$ \\
\hline & $1627 / 24576$ & $29 / 128$ & $1 / 4$ \\
\hline$I^{\beta}$ & $197 / 3072$ & $3 / 16$ & $5 / 16$ \\
\hline$M$ & $1 / 32$ & 0 & 1 \\
\hline
\end{tabular}

It is easy to see that method $\alpha$ is more labour intensive than $\beta$ under the three criteria. ${ }^{39}$ Moreover, if $r=50 \%$ and $\omega=1$, both methods coexist, since:

$$
\pi_{I}^{\alpha}=\pi_{I}^{\beta}=p_{I}^{*}=1
$$

It still needs to be ascertained that [A7] holds and LIC does not work. In effect:

$$
\left.\frac{d r^{\alpha}}{d w}\right|_{\omega=1}=-\frac{2832}{24997}>\left.\frac{d r^{\beta}}{d w}\right|_{\omega=1}=-\frac{336}{2939}
$$

\section{References}

Baldone, S. (2001), "A comment on Steedman", in T. Cozzi and R. Marchionatti (eds), Piero Sraffa's Political Economy: A centenary estimate, London: Routledge, pp. 359-361.

Bhaduri, A. and Marglin, S. (1990), Unemployment and the Real Wage: The Economic Basis for Contesting Political Ideologies, Cambridge Journal of Economics, 14(4), 375-393.

Bielschowsky, R. (2009), Sesenta años de la cepal: estructuralismo y neoestructuralismo, Revista CEPAL, 97, 173-194.

\footnotetext{
${ }^{39}$ In fact, $l_{I}^{\alpha}=\frac{1627}{24576}(\cong 0.066)>l_{I}^{\beta}=\frac{8}{105}(\cong 0.064)$, so Criterion 1 is satisfied; while $l_{I}^{\alpha}+m_{I}^{\alpha} l_{m}=$ $\frac{1801}{24576}(\cong 0.073)>l_{I}^{\beta}+m_{I}^{\beta} l_{m}=\frac{215}{3072}(\cong 0.070)$, and hence Criterion 2 is satisfied too. Finally, Criterion 3 is fulfilled since $\frac{p_{I}^{*}-p_{k}^{*}\left(k_{I}^{\alpha}+k_{m} m_{I}^{\alpha}\right)}{l_{I}^{\alpha}+m_{I}^{\alpha} l_{m}}=\frac{12864}{1801}(\cong 7.143)<\frac{p_{I}^{*}-p_{k}^{*}\left(k_{I}^{\beta}+k_{m} m_{I}^{\beta}\right)}{l_{I}^{\beta}+m_{I}^{\beta} l_{m}}=\frac{1536}{215}(\cong 7.144)$.
} 
Birolo, A. (1981), Mezzi di Produzione non prodotti e distribuzione del reddito in una economia aperta, Studi Economici, 16, 115-135.

Bresser Pereira, L.C. (2008), The Dutch desease and its neturalization: a Ricardian approach, Brasilian Journal of Political Economy, 28(1), 47-71.

Cesaratto, S. (2015), Neo-Kaleckian and Sraffian controversies on the theory of accumulation, Review of Political Economy, 27(2), 154-182.

Damill, M. and Frenkel, R. (2017), Symposium: Dilemmas of exchange rate and monetary policies in Latin America, Journal of Post Keynesian Economics, 40(1), 1-8.

Dvoskin, A. and Feldman, G. (2017a), Income Distribution and the Balance of Payments. A Formal Reconstruction of Some Argentinian Structuralist Contributions. Part I: Technical Dependency, Review of Keynesian Economics (forthcoming).

Dvoskin, A. and Feldman, G. (2017b), Income Distribution and the Balance of Payments. A Formal Reconstruction of Some Argentinian Structuralist Contributions. Part II: Financial Dependency, Review of Keynesian Economics (forthcoming).

Dvoskin, A. and Fratini, S. (2016), On Samuelson-Etula Master function and the capital controversy, European journal of the history of economic thought, 23(6), 1032-1058.

Dvoskin, A. and Petri, F. (2017), Again on the relevance of reverse capital deepening and reswitching, Metroeconomica, 68(4), 625-659.

Frenkel, R. and Ros, J. (2006), Unemployment and the Real Exchange Rate in Latin America, World Development, 34(4), 631-646.

Garegnani, P. (1978), Notes on consumption, investment and effective demand: I, Cambridge Journal of Economics, 2(4), 335-353.

Garegnani, P. (1983), The Classical Theory of Wages and the Role of Demand Schedules in the Determination of Relative Prices, American Economic Review, 73(2), 309-313.

Kurz, H. and Salvadori, N. (1995), Theory of Production, Cambridge: Cambridge University Press.

Lavoie, M. (1996), Traverse, Hysteresis, and Normal Rates of Capacity Utilization in Kaleckian Models of Growth and Distribution, Review of Radical Political Economics, 28(4), 113-147.

Lewis, A.W. (1954), Economic Development with Unlimited Supplies of Labour, The Manchester School, 22(2), 139-191.

Neto, A.S.M. and Lima, G.T. (2017), Competitive Exchange Rate and Public Infrastructure in a Macrodynamic of Economic Growth, Metroeconomica, 68(4), 792-815.

Oreiro, J.L., Missio, F., and Jayme Jr., F.G. (2015), Capital Accumulation, Structural Change and Real Exchange Rate in a Keynesian-Structuralist Growth Model, Panoeconomicus, 62(2), 237-256. 
Pariboni, R. (2016), Autonomous demand and the Marglin-Bhaduri model: a critical note, Review of Keynesian Economics, 4(4), 409-428.

Petri, F. (2004), General Equilibrium, Capital and Macroeconomics, London: Macmillan.

Rapetti, M. (2013), Macroeconomic Policy Coordination in a Competitive Real Exchange Rate Strategy for Development, Journal of Globalization and Development, 3(2), 1-31.

Rapetti, M. (2016), The Real Exchange Rate and Economic Growth: Some Observations on the Possible Channels, in M. Damill, M. Rapetti, and G. Rozenwurcel (eds), Macroeconomics and Development: Roberto Frenkel and the Economics of Latin America, New York: Columbia University Press, pp. 250-268.

Razmi, A. (2007), The Contractionary Short-Run Effects of Nominal Devaluation in Developing Countries: some Neglected Nuances, International Review of Applied Economics, 21(5), 577-602.

Razmi, A., Rapetti, M., and Skott, P. (2012), The Real Exchange Rate and Economic Development, Structural Change and Economic Dynamics, 23(2), 151-169.

Rodrik, D. (2008), The real exchange rate and economic growth, Brookings Papers on Economic Activity, 39(2), 365-439.

Ros, J. (2016), The Real Exchange Rate, the Real Wage, and Growth: A Formal Analysis of the "Development Channel", in M. Damill, M. Rapetti, and G. Rozenwurcel (eds), Macroeconomics and Development: Roberto Frenkel and the Economics of Latin America, New York: Columbia University Press, pp. 229-249.

Ros, J. and Skott, P. (1998), Dynamic effects of trade liberalization and currency overvaluation under conditions of increasing returns, The Manchester School, 66(4), 466-489.

Serrano, F. and Summa, R. (2015), Distribution and Cost-Push inflation in Brazil under inflation targeting, 1999-2014, Centro Sraffa Working Papers n. 14.

Sraffa, P. (1926), The Laws of Returns under Competitive Conditions, The Economic Journal, 36(144), 535-550.

Steedman, I. (1999), Production of Commodities by Means of Commodities and the Open Economy, Metroeconomica, 50(3), 260-276.

Tavares, M.D.C. (2000), Subdesenvolvimento, Dominação e Luta de Classes, in Tavares, M.D.C. (ed.), Celso Furtado e o Brasil, São Paulo: Fundação Perseu Abramo, pp. 129-154. 


\section{Authors contact information:}

Ariel Dvoskin

CONICET/National University of San Martín

Buenos Aires (Argentina)

advoskin@unsam.edu.ar

Germán David Feldman

National University of San Martín

Buenos Aires (Argentina)

gfeldman@unsam.edu.ar

Guido Ianni

CONICET/National University of San Martín

Buenos Aires (Argentina)

gianni@unsa.edu.ar 